\title{
Effect of lean manufacturing tools on sustainability: the case of Mexican maquiladoras
}

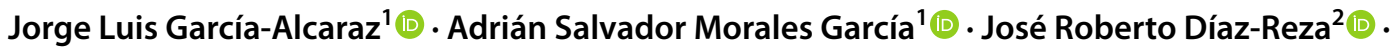 \\ Emilio Jiménez Macías ${ }^{3}\left[\right.$ (D) Carlos Javierre Lardies ${ }^{4}\left[\right.$. Julio Blanco Fernández ${ }^{5}$
}

Received: 4 August 2021 / Accepted: 27 January 2022 / Published online: 2 February 2022

(c) The Author(s), under exclusive licence to Springer-Verlag GmbH Germany, part of Springer Nature 2022

\begin{abstract}
The Mexican maquiladora industry is applying Lean Manufacturing Tools (LMT) in its production lines; however, few studies have investigated its relationship with sustainability (social, economic, and environmental). This paper presents a second-order structural equation model (SEM) relating 8 LMT integrated into three independent latent variables: continuous improvement (Kaizen and Gemba), supporting tools (Andon, visual management, and Poka-yoke), and machinery and equipment (total productive maintenance, overall equipment effectiveness, and Jidoka) that are related to social, economic, and environmental sustainability as dependent variables. The model is validated with information obtained from 249 companies using partial least squares. Findings show that the application of LMT in the Mexican maquiladora industry avoids the generation of waste and reprocessing. Likewise, the improvement of production processes reduces the waste emitted into the environment and reduces energy consumption. Also, when companies have environmental programs, the work environment is safe, and labor relations are improved, increasing morale and the commitment to work for the company, gaining economic and ecological benefits.
\end{abstract}

Keywords Lean manufacturing $\cdot$ Sustainability $\cdot$ Structural equations $\cdot$ Partial least squares

\section{Introduction}

The manufacturing industry in Mexico has grown in recent years. According to Manufacturing, Maquiladora, and Export Service Industry (IMMEX), in December 2020, there were 5138 companies, 498 were in Chihuahua state $(9.69 \%$

Responsible Editor: Philippe Garrigues

Jorge Luis García-Alcaraz

jorge.garcia@uacj.mx

Adrián Salvador Morales García

al194561@alumnos.uacj.mx

José Roberto Díaz-Reza

jose.dr01@itcj.edu.mx

Emilio Jiménez Macías

emilio.jimenez@unirioja.es

Carlos Javierre Lardies

sabicj1@unizar.es

Julio Blanco Fernández

julio.blanco@unirioja.es

1 Department of Industrial Engineering and Manufacturing, Autonomous University of Ciudad Juarez, Av. Del Charro of the national total), and 326 in Ciudad Juárez (6.34\% of the national total and $65.46 \%$ of the state total) (IMMEX, 2021). The manufacturing sector generates $2,689,209$ direct jobs nationwide, 477,480 occur in Chihuahua state $(17.75 \%$ of the national), and 316,619 in Ciudad Juárez (11.77\% of the federal and $66.31 \%$ of the state). Those values indicate the economic and social relevance of the manufacturing

450 Norte, Col. Partido Romero, Ciudad Juárez, Chihuahua, México Z.P. 32310

2 Department of Industrial Engineering, Instituto Tecnológico de Ciudad Juárez, Av. Tecnológico, Av. Tecnológico 1340. Fracc. El Crucero, Ciudad Juárez, Chihuahua, México Z.P. 32500

3 Department of Electrical Engineering, University of La Rioja, Luis de Ulloa 20, 26004 Logroño, La Rioja, Spain

4 Department of Mechanical Engineering, University of Zaragoza, María de Luna, Edif. Agustín de Betancourt s/n, 50018 Zaragoza, Aragon, Spain

5 Department of Mechanical Engineering, University of La Rioja, Luis de Ulloa 20, 26004 Logroño, La Rioja, Spain 
sector, and one of the essential subsectors is the maquiladora industry.

A maquiladora is defined as a subsidiary company with its headquarters in another country and characterized by carrying out activities with a high level of hand labor in Mexico, focusing on product and by-product assemblies. Maquiladoras in Mexico are closer geographically to the United States of America, one of the world's largest markets, and using the trade agreements with the USA and Canada, which allows them to import raw materials and export their products with low tariff rates.

With the arrival of maquiladora industries to Mexico, also, innovative production processes have arrived. Different administrative and operational tools are applied to be more competitive in a maquiladora, such as lean manufacturing (LM) for reducing waste (Faber, 2020). Lean manufacturing is also called lean production, which is a workplace organization method that focuses on the continuous improvement and optimization of the production system by eliminating waste and activities that do not add any value to the process (Maama et al., 2021). The LM objective is to minimize the losses in any manufacturing process and use only those essential resources.

LM is integrated by several tools grouped according to the specific scope to support standardization, continuous material flow, continuous improvement, machines and automation, human resource management, and all then are aimed to reduce waste. Thus, eliminating waste through LM improves quality and reduces manufacturing time and costs. Then, LM is associated with sustainability, and maquiladoras in Mexico must also be environmentally sustainable, respecting Mexican environmental and social norms and regulations.

There are currently studies regarding the relationship between LMT and sustainability from a qualitative and quantitative perspective. For example, Taucean et al. (2021) report a literature review on these two concepts, reporting similarities and how LMT complement each other; Ben Ruben et al. (2021) report a case where LM is implemented to reduce environmental impact and identify the barriers for its correct implementation. Younus et al. (2020) relate through the Spearman coefficient the relationship between LM, six sigma, and Environmental sustainability and companies' performance in Pakistan, finding that those methodologies are positively related. Other investigations analyze LMT generically; for example, Agrawal and Nath (2020) present a structural equation model (SEM) to measure the impact of LM and agility on companies' social sustainability and operational performance in India, ignoring economic aspects and generalizing the LM concept.

Antony et al. (2019) seek to relate waste from manufacturing processes through LM and relate it to green activities to generate Environmental sustainability. Henao et al. (2019) report a literature review and propose some scenarios about the LM implementation and the effects on the company's performance indices. Other studies are focus on relating only one LMT with sustainability. For example, Saurin et al. (2011) focus on analyzing cellular manufacturing and relate it to sustainability, indicating the role of plant layout for operational performance; Chen and Bidanda (2019) analyze JIT with inventory management and associate it with sustainable production; Morell-Santandreu et al. (2020) analyze Kaizen and relate it to sustainability in the health sector.

Therefore, it is observed that studies have been carried out aimed to relate the LM application with sustainability, some of them focused on environmental, social, and economic aspects, but all in an isolated way or focusing on certain LMT or generically integrating the concept of LM. However, LMTs are not implemented in isolation but are often implemented jointly, according to the companies' production requirements (de Oliveira et al., 2019).

Similarly, sustainability has been little studied in the maquiladora industry and its production processes. For example, Velázquez et al. (2006) report an analysis of the primary sustainability practices applied in the maquiladora industry; Velazquez et al. (2014) report the main pollution prevention and clean production practices applied in this industrial sector and their feasibility, integrating occupational aspects associated with employees. More recently, Munguía Vega et al. (2019) relate ergonomic and sustainability aspects, and finally, Morales-García et al. (2021) relate TPM and OEE with social sustainability in maquiladoras.

Therefore, there are two areas of opportunity. First, few studies consider the LMT implementation simultaneously in the analysis, relating it to sustainability. Second, LMTs are highly implemented in the maquiladora industry, and their relationship with sustainability has been little studied. However, the maquiladora industry is the most active industrial sector in northern Mexico, of great economic and social importance due to the monetary amount of imports and exports it performs and the labor force it employs.

To contribute to this research area, this article presents a second-order SEM in which eight LMTs are integrated into three independent latent variables, considering their simultaneous implementation: continuous improvement (Kaizen and Gemba), supporting tools (Andon, visual management, and Poka-yoke), and machinery and equipment (total preventive maintenance, overall equipment effectiveness, and Jidoka), which are related to environmental sustainability, where it is assumed that this, in turn, has an impact on social sustainability and together, impact economic sustainability as a latent dependent variable.

After this introduction, a literature review is presented in the "Literature and hypothesis review" section to justify the relationships proposed as hypotheses. The "Methodology" section offers the methodology followed. The "Results" 
section presents the analysis of results and implications, and finally, the conclusions and future works are presented.

\section{Literature and hypothesis review}

\section{Continuous improvement tools}

Continuous improvement $(C I)$ is aimed to analyze activities in the administrative and productive process to make adjustments to minimize errors and resource optimizations in organizations. $C I$ is part of the human being since he always tries to do his job better (Kiran, 2020), and in LM's house, it refers to the essential tools that must consistently be implemented first. Two LMTs measure this variable; the first is Kaizen, which seeks to manage daily change with the integration of all workers in the organization since they are the ones who best know the activities they carry out and how to improve them (Rossini et al., 2019). Therefore, supervisors must always be attentive to how operators carry out their activities to identify opportunity areas. It is recommended that all activities are duly standardized based on metrics that allow knowing the production process's situation to be compared (Arabeyyat et al., 2019). In this research, Kaizen is measured by five items. The final questionnaire is available at Morales-García et al. (2021).

The second CI tool is Gemba, which consists of adequately knowing every operation and its metrics, allowing to understand how the production process is carried out (Romero et al., 2020). While Kaizen focuses on improvements, Gemba in the production line generates a competitive advantage over competitors since it quickly monitors activities to know their situation (Liu \& Mouri, 2015). However, it is common to find those two concepts together, such as Gemba-Kaizen, wherewith a low application cost and common sense, they offer improvements (Dalton, 2019). Gemba is simple to execute, and there are currently reports of its application in areas other than manufacturing, such as the food industry (Suárez-Barraza et al. 2012). In this research, Gemba is measured by five items.

\section{Supporting tools}

Some of the LMTs are focused on preventing errors and facilitating the work of operators on production lines, so they support carrying out operations and maintaining a continuous flow of materials. In this research, supporting tools (ST) is measured by visual management (VM), Andon, and Poka-yoke (A., \& Eriksson, Y , 2018). Visual management consists of applying techniques and tools based on graphics and colors in production processes to know how to carry out their work autonomously, which focuses on simplifying communication visually (Makhija et al., 2021). An example of these visual aids is the quick guides and work procedures for carrying out a work, which clearly and concisely indicates how to do it. In the case of absenteeism, then, any operator who reads these instructions will carry out the work.

Specifically, visual management should focus on machine operators to indicate the operating procedures that everybody understands (Kurdve et al., 2019). Currently, it is used in construction and highways as safety signs (Tezel \& Aziz, 2017). For a literature review about VM applications, see Tezel et al. (2016). In this research, five items measure VM.

The second $S T$ is Andon, a broadly broadcast signal in a production system to indicate a specific situation that requires intervention, such as a colored light or sound (Free \& Cuganesan, 2021). Andon as a visual control in LM has changed the way of communicating within the company since operators based on an established color code or sounds quickly can identify any problem that has occurred and know what to do (Colazo, 2020). These fast actions allow having a standardized production process (Leffakis et al., 2020), which, in turn, impacts the company's performance (Moore et al., 2012). Five items measure Andon.

The third ST is Poka-yoke, which are devices or mechanisms that avoid human errors that later become defects and decrease the product's final quality (Saurin et al., 2012). Poka-yoke is focused on preventing and detecting errors, thus preventing a product from continuing the production line without being repaired (Barash, 1990). Pötters et al. (2018) conclude that Poka-yoke supports quality control in serial production systems or, as Abed et al. (2020) mentioned, it increases the process reliability by preventing defects.

Undoubtedly, the $S T$ (Andon, visual management, and Poka-yoke) have emerged as a response to a need or problem identified in production systems, where managers need to make visual or auditory notifications and illustrate how to do the work to the operators. That is, they are the product of improvement tools (Kaizen and Gemba), which is why the following hypothesis is proposed:

$H_{1}$. The implementation of LM continuous improvement tools directly and positively affects supporting tools in the maquiladora industry.

\section{Machinery and equipment}

In LM, there are tools focused on machinery and equipment (M\&E), so this variable integrates the TPM, OEE, and Jidoka. Concerning TPM, managers must ensure that machines and equipment are ready to operate at any time to avoid delays in set-up times and maintain the continuous 
flow since this practice has been shown to affect the company's performance directly [31]. However, they must carry out frequent inspections of the machines by specialized personnel and the worker to guarantee the machine's availability.

This availability in machines is calculated through the OEE, which measures their efficiency in the production lines; however, its estimate includes the quality of the generated product, so it can be said that TPM, OEE, and TQM are related (Singh et al., 2020). Thus, it also indicates the level of productivity of the production system and refers to know if production orders will be on time (Leksic et al., 2020). Thus, it also serves to indicate the level of productivity of the production system and as a reference to know if production orders will be generated on time.

Another critical tool in $M \& E$ is Jidoka, which refers to work automation. Preferentially, the machines must identify errors or metrics out of specifications and notify the operator through an Andon, facilitating maintenance and calibration (Romero et al., 2019). Currently, Jidoka plays a vital role as a bridge between LM and Industry 4.0 concepts, where data transfer is facilitated with automated machines (Fortuny-Santos et al., 2020) and also allows quick adjustments (SMED) to generate activities in the machines, which reduces cycle time (Mallampati et al., 2018).

Thus, machines and equipment require support tools that indicate how to operate them with visual management, stop them from avoiding the flow of defective products displayed through some Andon, or have error-proof systems implemented, such as Poka-yoke. Then the following hypothesis is proposed:

$H_{2}$. The implementation of LM supporting tools directly and positively affects machinery and equipment tools in the maquiladora industry.

\section{Environmental sustainability}

Sustainability is defined as a process that integrates activities focused on finding a balance between the environment, society, and the economic areas of the company through the appropriate use of resources. Specifically, in this research, we are focused on environmental sustainability, social sustainability, and economic sustainability. However, those kinds of sustainability are not independent, and Suh and Lee (2018) indicate some interactions among them; for example, social-environmental, eco-environmental, social-economic. In this research, no sustainability interactions are analyzed.

Environmental sustainability refers to meeting the needs of the present without compromising the ability of future generations to do so (Yadav et al., 2020). Companies must reduce the emission of solids and pollutants to the subsoil, water, and air, which harm the environment, which gives a negative image of them and their corporate reputation (Irfan et al., 2018).

To achieve an environmental sustainability $(E S)$, companies must also focus on the proper use of required energy to transform raw materials, reduce the consumption of harmful materials, comply with government certifications and regulations [48], and always look for improvements. To know the environmental impact from production processes and materials used, companies can carry out a life cycle analysis of them, identifying those that have the most significant negative impact (Campos-Guzmán et al., 2019) and on this, propose improvements through programs such as Kaizen and Gemba, for which the following hypothesis is proposed:

$\mathrm{H}_{3}$. The implementation of continuous improvement tools has a direct and positive effect on environmental sustainability in the maquiladora companies.

Another way to reduce negative environmental impacts is to avoid reprocessing raw material or subproducts due to operations poorly done (Abed et al., 2020). Also, notifications are not made to the operator through Andon, and production lines continue with defective products identified in the market or subsequent processes (Gillam et al., 2018). The maquiladora industry has a high level of human labor, where human errors in operations can generate much waste that can be avoided through Poka-yoke, visual management, or Andon. Thus, the following hypothesis is proposed:

$H_{4}$. The implementation of LM supporting tools has a direct and positive effect on the environmental sustainability in the maquiladora companies.

Another source of waste that requires energy and resources to operate is machinery and equipment; poor calibration due to low maintenance can generate products that do not meet quality specifications. Those raw materials must be reprocessed as far as possible and very frequently disposed of entirely with a negative environmental impact. Errors in the production system associated with $M \& E$ can be reduced if automated systems such as Jidoka stop the process when these specifications are not met in the product, minimizing defective products (Romero et al., 2019). Also, TPM and OEE are helpful tools that support $E S$ with adequate calibration and maintenance, so the following hypothesis is proposed:

$H_{5}$. The implementation of LM tools associated with machinery and equipment tools directly and positively affects environmental sustainability. 


\section{Social sustainability}

In this research, we assume that the main goal for a maquiladora is to generate economic benefits. Sustainability is only a means to achieve financial income and fulfill government regulations because they are established in Mexico due to low labor costs. The relationship between the different types of sustainability (social, environmental, and economic) has been studied by other authors. For example, Sarkar et al. (2021), using a SEM consider that social indicators are a consequence of environmental indicators and these, in turn, explain economic indicators.

Also, according to the sustainability concept, it indicates that companies should not compromise the needs of future generations, and that is the social category. In other words, companies must make responsible use of available resources and consider the well-being of their workers and society (Arslan, 2020). Improving the safety for employees, the relationships between them, increasing morale by showing that companies care about them, and creating a suitable work environment, companies gain social sustainability (SS) (Akbar \& Ahsan, 2020). Specifically, given that the maquiladora industry carries out activities that require high levels of labor hand (García-Alcaraz et al., 2020), then SS is of great importance since they have many employees.

Social sustainability in maquiladoras can be increased if companies demonstrate through actions that they are concerned about the health and safety of employees (Munguía Vega et al., 2019). Workers need to see that the company for which they work does not generate waste that it releases as pollution to air, wastewater drainage, or pollutant sound into the environment in which they live (Arredondo-Soto et al., 2018), so the following hypothesis is proposed:

$H_{6}$. The environmental sustainability of the maquiladora companies has a direct and positive effect on their social sustainability.

\section{Economic sustainability}

The ultimate goal in a company is to obtain economic sustainability to remain in the market, so its activities are simple means to achieve that purpose (Girón et al., 2020). In this research, we assume that $S S$ and $E S$ support economic sustainability $(E n S)$ because, traditionally, managers believe that financial growth, energy consumption, and health for workers negatively impact $E S$ (Sethi et al., 2020). However, Negulescu and Doval (2016) indicate that investment in social responsibility and sustainability are regulated in some countries, and companies must fulfill it.

If the employees in a company feel safe when developing their work and consider that they are not at risk, their morale increases, and they feel committed to generating quality products (Vaithyasubramanian et al., 2020). Workers with high morale reduce the number of defects and reprocess, which implies reducing production costs due to savings in energy and resources (Schönborn et al., 2019). Likewise, rejections of production orders by customers are reduced, and government regulations are complied with, which represents a reduction in transportation costs and administrative penalties (Alsayegh et al., 2020), which allows proposing the following hypothesis:

$H_{7}$. The social sustainability of a maquiladora company has a direct and positive effect on its economic sustainability.

Nowadays, environmental regulations are stringent. There are government offices in charge of supervising their compliance in all countries, and frequent expenditures are related to administrative sanctions for non-compliance with environmental regulations (Trujillo-Gallego \& Sarache, 2019). Suppose companies do not comply with environmental regulations. In that case, they lose reputation and acceptance in the eyes of society and their workers (Gámez \& González, 2016), and then, they lose customers, which affects their financial income (Morselli \& Ventura, 2017).

However, the use and management of hazardous materials in production processes also require a higher cost of transportation, transformation, and waste management (Shan \& Wang, 2019), and according to Uddameri and Honnungar (2010), the maquiladora industry requires to optimize the hazardous waste management and transportation for improving its cost. Therefore, the following hypothesis is proposed:

$H_{8}$. Environmental sustainability in a maquiladora company has a direct and positive effect on its economic sustainability.

Figure 1 graphically shows the relationships between variables and that appear as hypotheses.

\section{Methodology}

\section{Questionnaire development}

A literature review is carried out to identify previous research about the LMT and the sustainability they generate, which represents a rational validation. Items that indicate the implementation level for the LMT are identified, and the main associated indexes with the company's sustainability.

A first draft of the questionnaire is generated with five and ten items per lean manufacturing tool and by type of sustainability. However, since no previous questionnaires were applied to the maquiladora industry that addresses this issue, a judge's validation is also carried out with eight managers and three academics that help to adapt the first 
Fig. 1 Proposed model

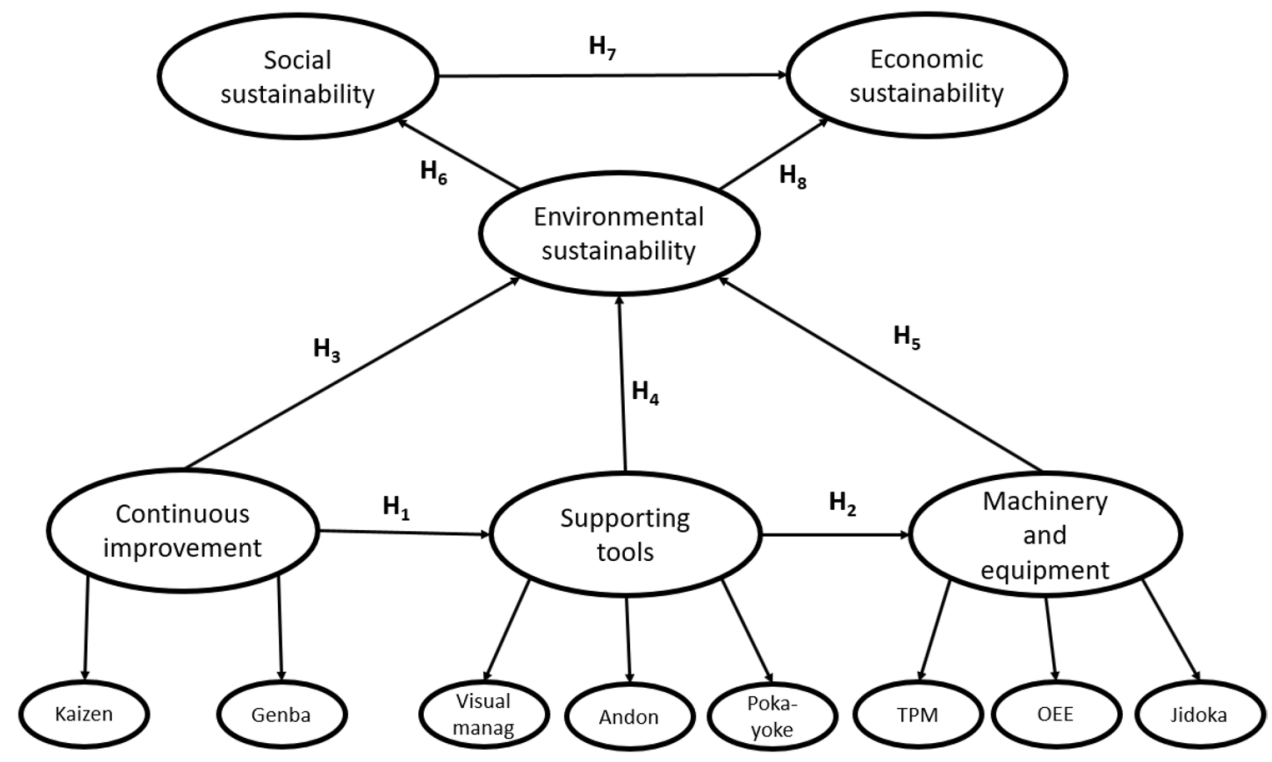

draft questionnaire in the maquiladora context. The final questionnaire version comprises three sections; the first one investigates demographic aspects such as gender, years of experience for the respondent, number of employees in the company, and industrial subsector. The second section focuses on the LMT, where there are ten items for continuous improvement (Kaizen -5, Gemba -5), fifteen for supporting tools (Andon 5, Poka-yoke 5, Andon 5), seventeen in machinery and equipment (TPM 7, EOO 5, Jidoka 5). The third section contains eight items on economic sustainability, six for social sustainability, and six for environmental sustainability.

The questionnaire is answered on a five-point Likert scale. One indicates that the activity is not carried out for LMT implementation or that the sustainable benefit is not obtained. Similarly, five indicates that the activity associated with LMT implementation is always done or that the sustainable benefit is always obtained. Intermediate values as 2, 3, and 4 are used for valuations like rarely, regularly, and almost always. The complete questionnaire used can be consulted at Morales García, García Alcaraz, et al. (2021).

\section{Application of the questionnaire}

Given the restrictions on access to maquiladora companies due to the contingency caused by COVID-19, the questionnaire is integrated into a specialized electronic platform, where respondents are forced to answer all the questions to avoid missing values. The inclusion criteria are that respondents must be working in the maquiladora industry, have at least two years of experience, and belong to a department associated with production and maintenance to guarantee knowledge regarding the LMT implementation and the benefits obtained.
An email is sent to potential respondents, inviting them to participate in the research, and an electronic link is added to access the questionnaire. If, after two weeks, no response is obtained, a second email is sent, and if it is not responded to again, that case is skipped. The platform remains open to receive responses from respondents from May 15 to November 15, 2020.

\section{Obtaining the information and debugging}

A database in Excel format is downloaded from the specialized electronic platform that contains the questionnaire, which is then analyzed in the technical software SPSS V.25® and the final dataset is available at Morales García, Garcia Alcaraz, et al. (2021). The debugging focuses on the following two activities:

1. Identification of extreme values. Each item is standardized, where values greater than 4 in absolute value are considered atypical and replaced by the median in that item (Hoffman, 2019).

2. Identification of non-committed respondents, for which the standard deviation of each of the cases answered is obtained. This operation is done only for the second and third sections in the questionnaire and eliminates cases lower than 0.5 in standard deviation (Kock, 2019a).

\section{Descriptive analysis of the sample and items}

Cross-tables are made with demographic data to characterize the sample. As a descriptive analysis for the items, the median is calculated as a measure of central tendency. Median is used because data is obtained on an ordinal scale (Iacobucci et al., 2015). High values indicate that the activity 
associated with LMT is always carried out or that the sustainable benefit is always obtained. In contrast, low values indicate that the activity associated with LMT is not carried out or that the benefit is not obtained.

Likewise, the interquartile range is estimated as a dispersion measure. High values indicate a lower consensus among respondents concerning the mean value of the item, and low values indicate an agreement among respondents.

\section{Latent variable validation}

Before integrating the latent variables into the SEM, the validation process for each one is carried out by estimating the following indices (Kock, 2018).

- $R^{2}$ and adjusted $R^{2}$ to measure parametric predictive validity, and the value of these is required to be greater than 0.02 .

- Composite reliability index and Cronbach's alpha to measure the internal validity of the variables and values greater than 0.6 are accepted since this is an exploratory study in the maquiladora sector.

- The average variance extracted (AVE) to measure convergent validity and values greater than 0.5 is accepted.

- $Q^{2}$ to measure non-parametric predictive validity and values similar to those of $R^{2}$ squared are required.

- Variance inflation factor $(V I F)$ to measure collinearity within each latent variable and values less than five are accepted.

For other validation indices for latent variables, please see the supplementary material with the following reports: $T$ ratios for path coefficients (values higher than 1.96 are better), the confidence interval for path coefficients (intervals must not include zero), $T$ ratios for loadings (values higher than 1.96 are better), confidence intervals for loadings (intervals must be greater than 0.5 ), additional reliability coefficients, correlations among latent variables with squared roots of AVEs (for discriminant validity), PLSc reliabilities, Dijkstra's rho's, full collinearity VIFs and HTMT ratios.

\section{Structural equation analysis}

To validate the hypotheses raised in Fig. 1, the Structural Equation Modeling (SEM) technique based on partial least squares (PLS) and, specifically, the software WarpPLS v.7.0® are used. SEM technique is selected because it has been applied in similar analyses by Garcia-Alcaraz et al. (2017) to analyze the impact of ICT on supply chain performance and by Avelar-Sosa et al. (2018) to model manufacturing practices' effects on delivery time. In addition, PLS is recommended when responses are in an ordinal scale, with small samples and data with non-normal distributions in the items (Kock, 2019b).

The following model efficiency and quality indices are analyzed before the SEM interpretation, considering a confidence level of 95\% (Kock, 2019a):

- The average path coefficient $(A P C)$ measures the significance of the regression indices of the model, and the associated $P$ value must be less than 0.05 .

- Average $R$-squared (ARS) and average adjusted $R$-squared $(A A R S)$ measure the model's predictive validity in the latent dependent variables, and the associated $P$ value must be less than 0.05 .

- Average block VIF (AVIF) and average full collinearity $V I F(A F V I F)$ measure the collinearity between the latent variables and must be less than 5 .

- Tenenhaus GoF $(G o F)$ measures the data fit in the SEM and must be greater than 0.36 .

If the model is validated, then three types of effects are interpreted in the proposed relationships. The direct effects validate the hypotheses in Fig. 1, obtaining a standardized $\beta$ value to measure the dependence between an independent latent variable and another dependent one. To test the direct effects or hypotheses statistically, the null hypothesis $H_{0}$ proposes that $\beta=0$ is contrasted versus the alternative hypothesis $H_{1}$ that $\beta \neq 0$. If it is statistically proven with a confidence level of $95 \%$ that $\beta=0$, then it is concluded that there is no direct relationship between the analyzed variables. However, if it is proven that $\beta \neq 0$, then it is assumed that there is a relationship between them, regardless of the sign of $\beta$ (Farooq et al., 2018).

The second effects analyzed are the indirect effects between the independent and dependent latent variables. These effects occur through mediating variables that can be of two or more segments. Likewise, $\beta$ values are calculated, and statistical tests are performed at $95 \%$ confidence. The interpretation of indirect effects is interesting when they are statistically significant, and the direct effects have not been, indicating the importance of mediating variables.

Finally, the total effects are estimated. These result from the sum of the direct and indirect effects and a $\beta$-value is also calculated for everyone. Likewise, each effect (direct, indirect, and total) is associated with an effect size (Es) to measure the variance explained by the independent variable in the dependent variable. The sum of the effect sizes on the dependent variables equals the value of $\mathrm{R}$ squared.

\section{Sensitivity analysis}

WarpPLS v.7® performs its operations with standardized values and allows obtaining the probability of variables in an isolated, joint, and conditional manner at different levels. 
Table 1 Position held and years of experience

\begin{tabular}{lllll}
\hline $\begin{array}{l}\text { Years of } \\
\text { experience }\end{array}$ & Position & & Total \\
\cline { 2 - 4 } & Manager & Engineer & Supervisor & \\
\hline $2-5$ & 52 & 97 & 21 & 170 \\
$5-10$ & 10 & 20 & 3 & 33 \\
+10 & 18 & 7 & 11 & 36 \\
Total & 80 & 124 & 35 & 239 \\
\hline
\end{tabular}

In this research, a variable is considered to have a high probability of occurrence if the standardized $Z$ value is greater than $1[P(Z>1)]$ or low if the standardized value is less than $-1[P(Z<-1)]$. The joint probabilities are represented by " $\&$ " and the following are estimated: $P\left(Z_{\mathrm{i}}>1\right) \cap P\left(Z_{\mathrm{d}}>1\right)$, $P\left(Z_{\mathrm{i}}>1\right) \cap P\left(Z_{\mathrm{d}}<-1\right), P\left(Z_{\mathrm{i}}<-1\right) \cap P\left(Z_{\mathrm{d}}>1\right)$, and $P\left(Z_{\mathrm{i}}<-1\right) \cap P\left(Z_{\mathrm{d}}<-1\right)$. The conditional probabilities estimated are $P\left(Z_{\mathrm{d}}>1\right) / P\left(Z_{\mathrm{i}}>1\right), P\left(Z_{\mathrm{d}}>1\right) / P\left(Z_{\mathrm{i}}<-1\right)$, $P\left(Z_{\mathrm{d}}<-1\right) / P\left(Z_{\mathrm{i}}>1\right)$, and $P\left(Z_{\mathrm{d}}<-1\right) / P\left(Z_{\mathrm{i}}<-1\right)$, where $Z_{\mathrm{i}}$ represents an independent variable and $Z_{d}$ represents a dependent variable from the model in Fig. 1.

\section{Results}

\section{Descriptive analysis of the sample}

A total of 257 responses to the questionnaire were collected from 555 emails sent, and the response rate was
46.06\%. However, 18 were discarded, associated with respondents not committed or not meet the inclusion requirements for 239 to be analyzed, so the utilizable rate was $42.88 \%$. Eighty-nine responders were women, and 150 were men.

Table 1 illustrates the years of experience and the position hold by responders. The majority observed that 124 $(51.88 \%)$ are engineers. Engineers plus managers add up to $204(85.35 \%)$, indicating that the information comes from people who hold high management positions in maquiladoras. Likewise, it is observed that $170(71.13 \%)$ have between two and five years in their job position.

Table 2 illustrates the number of respondents who answered the questionnaire and the industrial subsector to which they belong, so it is concluded that most of the respondents work for automotive, machining, and electrical/ electronic companies. Likewise, it is observed that the companies are relatively large since 88 of them have between 1000 and 5000 workers in their production lines. Readers interested in the descriptive analysis of items with medians and interquartile ranges see the supplementary material.

\section{Validation of latent variables}

Table 3 illustrates the validation indices for the secondorder latent variables. However, some items are eliminated to improve Cronbach's alpha index in latent variables, and Table 3 displays the validation indexes. In the questionnaire in Annex 1, the items eliminated from the analysis are indicated with "*."
Table 2 Industrial sector and company size

\begin{tabular}{llllllll}
\hline Sector & \multicolumn{9}{l}{ Number of employees } & \multirow{2}{*}{ Total } \\
\cline { 2 - 6 } & $<50$ & $50<300$ & $300<1000$ & $1000<5000$ & $5000<10,000$ & $>10,000$ & \\
\hline Automotive & 4 & 8 & 11 & 43 & 9 & 11 & 86 \\
Machining & 15 & 12 & 13 & 20 & 0 & 0 & 60 \\
Electric/electronics & 5 & 8 & 11 & 20 & 5 & 1 & 50 \\
Plastic & 7 & 4 & 12 & 0 & 0 & 0 & 23 \\
Medical & 2 & 1 & 2 & 5 & 5 & 5 & 20 \\
Total & 33 & 33 & 49 & 88 & 19 & 17 & 239 \\
\hline
\end{tabular}

Table 3 Latent variable validation

\begin{tabular}{llllllll}
\hline Index & $\begin{array}{l}\text { Best } \\
\text { value if }\end{array}$ & EnS & SS & $E S$ & $C I$ & $S T$ & $M \& E$ \\
\hline$R$-squared & $>0.02$ & 0.602 & 0.453 & 0.398 & & 0.535 & 0.687 \\
Adjusted $R$-squared & $>0.02$ & 0.599 & 0.451 & 0.390 & & 0.533 & 0.685 \\
Composite reliability & $>0.7$ & 0.938 & 0.948 & 0.948 & 0.898 & 0.806 & 0.852 \\
Cronbach's alpha & $>0.7$ & 0.917 & 0.927 & 0.927 & 0.772 & 0.637 & 0.739 \\
Average variance extracted & $>0.5$ & 0.750 & 0.821 & 0.821 & 0.814 & 0.589 & 0.659 \\
Full collinearity VIF & $<5$ & 2.783 & 2.951 & 2.111 & 2.443 & 3.575 & 4.114 \\
$Q$-squared & $>0.02$ & 0.603 & 0.453 & 0.400 & & 0.535 & 0.687 \\
\hline
\end{tabular}


Findings indicate that the latent variables have sufficient parametric predictive validity since the $R$-squared and adjusted $R$-squared indices are greater than 0.02 ; however, there is non-parametric predictive validity in latent variables since the $Q$-squared values are similar to $R$-squared. Also, the composite reliability indices and Cronbach's alpha are greater than 0.6 , indicating content validity. The average variance extracted is bigger than 0.5 in all the latent variables, concluding that there is convergent validity. Finally, the total collinearity VIF is lower than 5, indicating the absence of collinearity problems. Based on those results, the variables are integrated into the SEM.

\section{Structural equation model}

The SEM is evaluated according to the methodology described. Before interpreting the model, its efficiency indices are validated. Findings indicate that the model has sufficient predictive validity since the $P$ values associated with $A R S$ and $A A R S$ are lower than 0.001 , and the $\beta$ value is significant since the $A P C$ has an associated $P$ value lower than 0.001 . Likewise, there are no collinearity problems between the analyzed variables since the $A V I F$ and $A F V I F$ values are lower than 5. Finally, observe that the data have an acceptable fit for the model since the GoF is large enough.

- Average path coefficient $(A P C)=0.469, P<0.001$

- Average $R$-squared $(A R S)=0.535, P<0.001$

- Average adjusted $R$-squared $(A A R S)=0.532, P<0.001$

- Average block $V I F(A V I F)=2.686$, acceptable if $\leq 5$

- Average full collinearity VIF $(A F V I F)=2.996$, acceptable if $\leq 5$

- Tenenhaus $G o F(G o F)=0.630$, large if $\geq 0.36$

\section{Direct effects}

Figure 2 illustrates the evaluated model with the standardized $\beta$ indices, their associated $P$ values, and the $R^{2}$ values for the dependent variables. Given that conclusions are made with a $95 \%$ of confidence level, it is observed that seven hypotheses are statistically supported, while one is not, although it is decided to preserve the relationship to evaluate the indirect and total effect.

Here it is essential to mention that an analysis was performed to determine the sample size required based on the smallest $\beta$ value that is statistically significant, a confidence level of $95 \%$, and a power level of $80 \%$. It was found that the minimum sample size should be 117 . In this research, the sample is 238 , so we conclude that the sample is adequate and proceed to the model interpretation. Table 4 summarizes the indices, indicating the $\beta$ values and their $P$ values, the effect size, and a conclusion regarding the hypotheses.

As an example, concerning $H_{1}$, it can be said that there is enough statistical evidence to declare with a confidence

Table 4 Summary of direct effects

\begin{tabular}{lllll}
\hline$H_{\mathrm{i}}$ & Relationship & $\beta(P$ value $)$ & Effect size & Conclusion \\
\hline$H_{1}$ & $C I \rightarrow S T$ & $0.731(P<0.001)$ & 0.535 & Supported \\
$H_{2}$ & $S T \rightarrow M \& E$ & $0.829(P<0.001)$ & 0.687 & Supported \\
$H_{3}$ & $C I \rightarrow E S$ & $0.232(P<0.001)$ & 0.130 & Supported \\
$H_{4}$ & $S T \rightarrow E S$ & $0.045(P=0.246)$ & 0.025 & Not supported \\
$H_{5}$ & $M \& E \rightarrow E S$ & $0.399(P<0.001)$ & 0.243 & Supported \\
$H_{6}$ & $E S \rightarrow S S$ & $0.673(P<0.001)$ & 0.453 & Supported \\
$H_{7}$ & $S S \rightarrow E n S$ & $0.545(P<0.001)$ & 0.405 & Supported \\
$H_{8}$ & $E S \rightarrow E n S$ & $0.298(P<0.001)$ & 0.197 & Supported \\
\hline
\end{tabular}

Fig. 2 Evaluated model

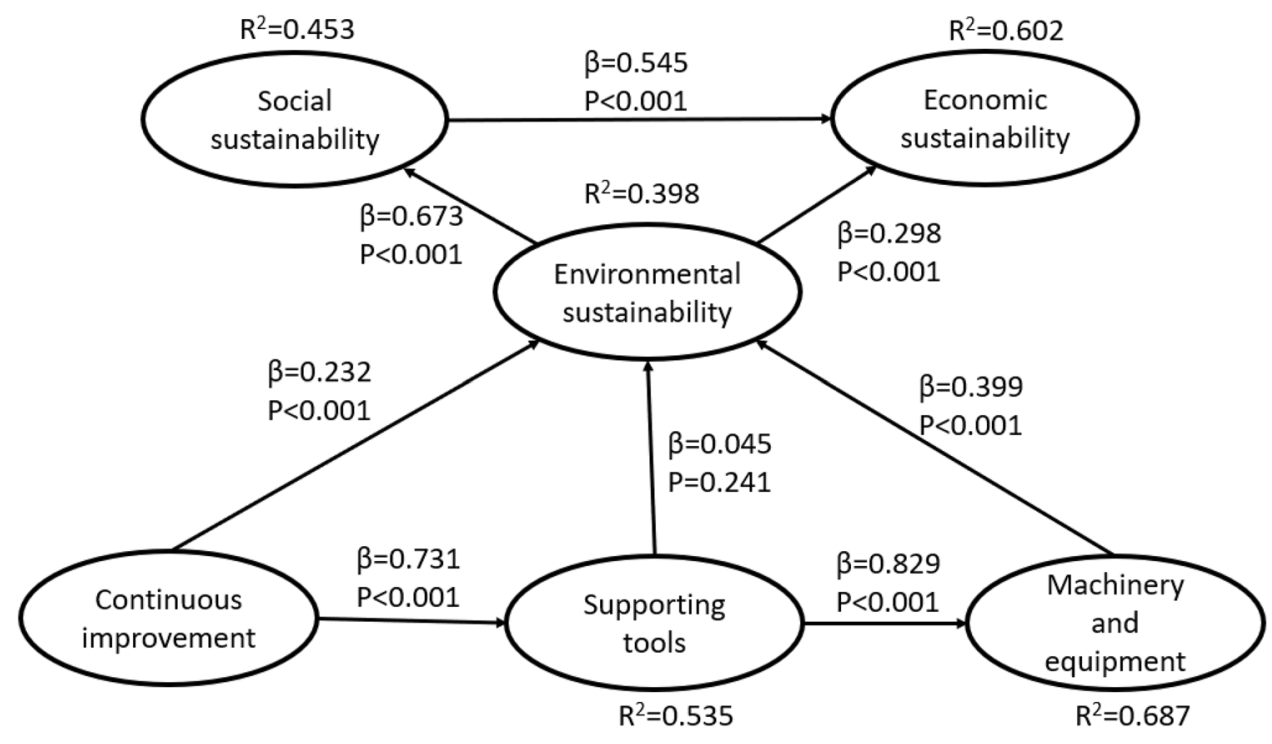


level of $95 \%$ that continuous improvement has a direct and positive effect on supporting tools since when the first variable increases its standard deviation in one unit, the second one goes up by 0.731 units. $C I$ can explain $53.5 \%$ of the variability contained in $S T$. The other relationships are interpreted similarly, and a deep interpretation is given in the "Discussion of results and conclusions" section.

\section{Sum of indirect and total effects}

The sum of indirect and total effects appears in Table 5. Observe that all effects are statistically significant and hence the importance of preserving the relationship $S T \rightarrow E S$, where the direct effect is statistically non-significant. However, the sum of indirect and total effects has been. That indirect effect occurs through $M \& E$ as a mediating variable. In conclusion, $S T$ like Poka-yoke, visual management, and Andon generate $E S$ but through $M \& E$, since they facilitate their use and control, avoiding reprocessing, waste, and products with low quality.

\section{Sensitivity analysis}

Table 6 reports the sensitivity analysis for the relationships established as hypotheses and all the LMTs with the ES, SS, and $E n S$. However, the LMT probabilities with the different types of sustainability have also been calculated, although there is no direct effect between them. The sign "-" indicates low levels for a latent variable in a scenario and high levels by " + ". Observe that the probability that $C I+$ occurs independently is 0.180 , but that $C I-$ occurs is 0.146 . The probability that $C I+$ and $E n S+$ occur together is only 0.079 , but that $E n S+$ occurs given that $C I+$ has occurred is 0.442 , which indicates the high dependence between those variables.

Also, observe that there is no probability that $C I+$ occurs with $E n S-$, since the associated probabilities are zero, jointly or conditionally. A similar condition is observed for $E n S+$ with $C I$, which means that $C I+$ always generates $E n S+$ to the maquiladoras. Finally, the probability that $E n S$ - occurs given that $C I$ - has happened is 0.400 , representing a risk for the company. The other relationships between variables are interpreted similarly and are analyzed in the "Discussion of results and conclusions" section.

\section{Discussion of results and conclusions}

\section{From the structural equation model}

In Fig. 2, in five latent variables appear an $R^{2}$ value associated, measuring the explanatory power of the independent variables on the dependent variables. For example, $S T$ is explained in $53.5 \%$ by $C I$, while it explains $M \& E$ in $68.7 \%$, and these relationships are straightforward since there is only one independent variable. However, $E S$ is explained in $39.8 \%$, but $13.0 \%$ comes from $C I, 2.5 \%$ from $S T$, and $24.3 \%$ from $M \& E$, which indicates that this last variable is the most important to explain $E S$, which makes sense since in $M \& E$ is where mistakes of quality are made that require rework or
Table 5 Sum of indirect and total effects

\begin{tabular}{|c|c|c|c|c|c|}
\hline & $S S$ & $E S$ & $C I$ & $S T$ & $M \& E$ \\
\hline \multicolumn{6}{|c|}{ Sum of indirect effects } \\
\hline EnS & & $\begin{array}{l}0.367(P<0.001) \\
E S=0.243\end{array}$ & $\begin{array}{l}0.337(P<0.001) \\
E S=0.206\end{array}$ & $\begin{array}{l}0.250(P<0.001) \\
E S=0.161\end{array}$ & $\begin{array}{l}0.265(P<0.001) \\
E S=0.182\end{array}$ \\
\hline$S S$ & & & $\begin{array}{l}0.341(P<0.001) \\
E S=0.206\end{array}$ & $\begin{array}{l}0.253(P<0.001) \\
E S=0.163\end{array}$ & $\begin{array}{l}0.269(P<0.001) \\
E S=0.192\end{array}$ \\
\hline$E S$ & & & $\begin{array}{l}0.275(P<0.001) \\
E S=0.154\end{array}$ & $\begin{array}{l}0.331(P<0.001) \\
E S=0.181\end{array}$ & \\
\hline$M \& E$ & & & $\begin{array}{l}0.606(P<0.001) \\
E S=0.434\end{array}$ & & \\
\hline \multicolumn{6}{|c|}{ Total effects } \\
\hline EnS & $\begin{array}{l}0.545(P<0.001) \\
E S=0.405\end{array}$ & $\begin{array}{l}0.665(P<0.001) \\
E S=0.440\end{array}$ & $\begin{array}{l}0.337(P<0.001) \\
E S=0.206\end{array}$ & $\begin{array}{l}0.250(P<0.001) \\
E S=0.161\end{array}$ & $\begin{array}{l}0.265(P<0.001) \\
E S=0.182\end{array}$ \\
\hline$S S$ & & $\begin{array}{l}0.673(P<0.001) \\
E S=0.453\end{array}$ & $\begin{array}{l}0.341(P<0.001) \\
E S=0.206\end{array}$ & $\begin{array}{l}0.253(P<0.001) \\
E S=0.163\end{array}$ & $\begin{array}{l}0.269(P<0.001) \\
E S=0.192\end{array}$ \\
\hline$E S$ & & & $\begin{array}{l}0.507(P<0.001) \\
E S=0.284\end{array}$ & $\begin{array}{l}0.376(P<0.001) \\
E S=0.206\end{array}$ & $\begin{array}{l}0.399(P<0.001) \\
0.243\end{array}$ \\
\hline$M \& E$ & & & $\begin{array}{l}0.606(P<0.001) \\
E S=0.434\end{array}$ & $\begin{array}{l}0.829(P<0.001) \\
E S=0.687\end{array}$ & \\
\hline$S T$ & & & $\begin{array}{l}0.731(P<0.001) \\
E S=0.535\end{array}$ & & \\
\hline
\end{tabular}


Table 6 Sensitivity analysis

\begin{tabular}{|c|c|c|c|c|c|c|c|c|c|c|c|}
\hline Level & & $\mathrm{CI}+$ & $C I-$ & $S T+$ & $S T-$ & $M \& E+$ & $M \& E-$ & $E S+$ & $E S-$ & $S S+$ & $S S-$ \\
\hline & Probability & 0.180 & 0.146 & 0.146 & 0.176 & 0.138 & 0.142 & 0.159 & 0.151 & 0.205 & 0.159 \\
\hline$E n S+$ & 0.151 & $\begin{array}{l}\&=0.079 \\
I f=0.442\end{array}$ & $\begin{array}{l}\&=0.000 \\
I f=0.000\end{array}$ & $\begin{array}{l}\&=0.075 \\
I f=0.514\end{array}$ & $\begin{array}{l}\&=0.000 \\
I f=0.000\end{array}$ & $\begin{array}{l}\&=0.075 \\
I f=0.545\end{array}$ & $\begin{array}{l}\&=0.000 \\
I f=0.000\end{array}$ & $\begin{array}{l}\&=0.084 \\
I f=0.526\end{array}$ & $\begin{array}{l}\&=0.004 \\
I f=0.028\end{array}$ & $\begin{array}{l}\&=0.088 \\
I f=0.429\end{array}$ & $\begin{array}{l}\&=0.000 \\
I f=0.000\end{array}$ \\
\hline$E n S-$ & 0.138 & $\begin{array}{l}\&=0.000 \\
I f=0.000\end{array}$ & $\begin{array}{l}\&=0.059 \\
I f=0.400\end{array}$ & $\begin{array}{l}\&=0.000 \\
I f=0.000\end{array}$ & $\begin{array}{l}\&=0.079 \\
I f=0.452\end{array}$ & $\begin{array}{l}\&=0.000 \\
I f=0.000\end{array}$ & $\begin{array}{l}\&=0.071 \\
I f=0.500\end{array}$ & $\begin{array}{l}\&=0.004 \\
I f=0.026\end{array}$ & $\begin{array}{l}\&=0.075 \\
I f=0.500\end{array}$ & $\begin{array}{l}\&=0.000 \\
I f=0.000\end{array}$ & $\begin{array}{l}\&=0.084 \\
I f=0.526\end{array}$ \\
\hline$S S+$ & 0.205 & $\begin{array}{l}\&=0.063 \\
\text { If }=0.349\end{array}$ & $\begin{array}{l}\&=0.013 \\
I f=0.086\end{array}$ & $\begin{array}{l}\&=0.079 \\
I f=0.543\end{array}$ & $\begin{array}{l}\&=0.008 \\
I f=0.048\end{array}$ & $\begin{array}{l}\&=0.075 \\
I f=0.545\end{array}$ & $\begin{array}{l}\&=0.000 \\
\text { If }=0.000\end{array}$ & $\begin{array}{l}\&=0.084 \\
\text { If }=0.526\end{array}$ & $\begin{array}{l}\&=0.008 \\
I f=0.056\end{array}$ & & \\
\hline$S S-$ & 0.159 & $\begin{array}{l}\&=0.000 \\
\text { If }=0.000\end{array}$ & $\begin{array}{l}\&=0.075 \\
I f=0.514\end{array}$ & $\begin{array}{l}\&=0.000 \\
I f=0.00\end{array}$ & $\begin{array}{l}\&=0.100 \\
I f=0.571\end{array}$ & $\begin{array}{l}\&=0.000 \\
I f=0.000\end{array}$ & $\begin{array}{l}\&=0.084 \\
\text { If }=0.588\end{array}$ & $\begin{array}{l}\&=0.000 \\
I f=0.000\end{array}$ & $\begin{array}{l}\&=0.092 \\
I f=0.611\end{array}$ & & \\
\hline$E S+$ & 0.159 & $\begin{array}{l}\&=0.075 \\
\text { If }=0.419\end{array}$ & $\begin{array}{l}\&=0.013 \\
I f=0.086\end{array}$ & $\begin{array}{l}\&=0.059 \\
I f=0.400\end{array}$ & $\begin{array}{l}\&=0.004 \\
I f=0.024\end{array}$ & $\begin{array}{l}\&=0.050 \\
I f=0.364\end{array}$ & $\begin{array}{l}\&=0.004 \\
\text { If }=0.029\end{array}$ & & & & \\
\hline$E S-$ & 0.151 & $\begin{array}{l}\&=0.004 \\
\text { If }=0.023\end{array}$ & $\begin{array}{l}\&=0.071 \\
I f=0.486\end{array}$ & $\begin{array}{l}\&=0.000 \\
I f=000\end{array}$ & $\begin{array}{l}\&=0.071 \\
I f=0.405\end{array}$ & $\begin{array}{l}\&=0.000 \\
I f=0.000\end{array}$ & $\begin{array}{l}\&=0.079 \\
\text { If }=0.559\end{array}$ & & & & \\
\hline$M \& E+$ & 0.138 & $\begin{array}{l}\&=0.084 \\
I f=0.465\end{array}$ & $\begin{array}{l}\&=0.000 \\
I f=0.000\end{array}$ & $\begin{array}{l}\&=0.096 \\
I f=0.657\end{array}$ & $\begin{array}{l}\&=0.000 \\
I f=0.000\end{array}$ & & & & & & \\
\hline$M \& E-$ & 0.142 & $\begin{array}{l}\&=0.000 \\
\text { If }=0.000\end{array}$ & $\begin{array}{l}\&=0.079 \\
I f=0.543\end{array}$ & $\begin{array}{l}\&=0.000 \\
I f=0.000\end{array}$ & $\begin{array}{l}\&=0.096 \\
I f=0.548\end{array}$ & & & & & & \\
\hline$S T+$ & 0.146 & $\begin{array}{l}\&=0.088 \\
\text { If }=0.488\end{array}$ & $\begin{array}{l}\&=0.004 \\
I f=0.029\end{array}$ & & & & & & & & \\
\hline$S T-$ & 0.176 & $\begin{array}{l}\&=0.004 \\
\text { If }=0.029\end{array}$ & $\begin{array}{l}\&=0.092 \\
I f=0.629\end{array}$ & & & & & & & & \\
\hline
\end{tabular}

will become waste. Also, ES explains $45.3 \%$ of $S S$, but $E n S$ is explained in $60.2 \%$ by $S S$ with $40.5 \%$ and $E S$ with $19.7 \%$, which indicates the importance of $S S$ to achieve $E n S$.

In the $C I \rightarrow S T$ relationship for $H_{1}$, the $\beta$ value is 0.731 , the second-highest in the model, indicating that promoting supervision in the workplace, sampling for quality levels to monitor production processes, the managers' involvement, and opinions from employees in plant operations will always result in proposals that facilitate the work. However, Andon, Poka-yoke, and visual management implementation avoid generating waste and reprocessing, which agrees with the report by Romero et al. (2020).

For the relationship between $S T \rightarrow M \& E$ in $H_{2}$, the $\beta$ value is 0.829 , the highest in the model, so it is concluded that Andon, visual management, and Poka-yoke facilitate the maintenance process and operation of equipment by employees and specialized personnel in the maquiladora. Also, $S T$ increases efficiency and availability rates in machinery and facilitates automation processes that allow errors to be identified quickly and avoid products without quality specifications. The previous findings agree with Paroutis and Knight (2019), who consider that visual management is essential in a TPM strategy to facilitate the operation of machines.

Regarding $\mathrm{H}_{3}$ in $\mathrm{CI} \rightarrow E S$, the direct effect surprises since it is low with a $\beta=0.232$, but when analyzing the indirect effects through $S T$ and $M \& E$, that is 0.275 and higher than the direct effect, which gives a total effect of 0.507 , demonstrating the importance of $M \& E$ in the generation of $E S$.
Promoting the improvement of production processes with managers and operators' involvement allows reducing solid, liquid, and gas wastes that are emitted into the environment, reduces energy consumption for the transformation of raw material through $M \& E$, and decreases the use of hazardous or harmful materials.

The relationship that was not statistically significant was $S T \rightarrow E S$ in $H_{4}$ since the associated $P$ value is 0.241 and $\beta=0.045$. In other words, the use of Poka-yoke, visual management, and Andon in the production system does not decrease in solid, liquid, and gas emissions to the environment directly. The relationship is indirect and occurs through $M \& E$ as a mediating variable with a $\beta=0.331$, giving a total of 0.376 , and both are statistically significant. The initial findings confirm the importance of adequately calibrated equipment, high efficiency, and availability in machines and automated systems to detect quality errors on time (Sahoo, 2019).

The importance of $M \& E$ has been demonstrated as a mediating variable. However, its relationship with $E S$ in $H_{5}$ is significant with $\beta=0.339$, which confirms the importance of calibrating equipment that does not generate outof-specification products that later are requiring reprocess (Martínez-Loya et al., 2018). Those calibrated machines avoid defective products to continue their flow in the production line; however, using Jidoka tools, those defects can be detected, as indicated by Tekin et al. (2019). If low quality is generated in the production system, then subproducts need to be reprocessed, spending energy, raw materials that 
sometimes are waste and generate an environmental impact if discarded.

Another high relationship according to its direct effect is $E S \rightarrow S S$ in $H_{6}$ since it has a $\beta=0.673$. That value indicates that when a company has programs focused on reducing the emission of pollutants into the environment and making rational use of energy, employees consider that their work environment is safe, that their health is not compromised when carrying out their activities, and that relationships among partners at all levels are improved. Under those circumstances, social commitment increases employee morale and commitment to work for the company's benefit, and according to Vaithyasubramanian et al. (2020), the social and environmental aspects should not be separated. Our findings support the report from Ajibike et al. (2021), where social and environmental sustainability are related.

However, it is necessary to understand that LMT, SS, and $E S$ are the only means to achieve $E n S$, as Maama et al. [3] indicated. In the first instance, please observe that the relationship $S S \rightarrow E n S$ in $H_{7}$ the $\beta$ value of 0.545 is statistically significant and indicates that when working conditions are improved for employees, they feel safe when carrying out their activities, and their health is improved not at risk. SS generates a high motivation and morale that translates into a higher $E n S$ by reducing costs associated with new products, production processes with less waste, and orders without rejection by the client. Likewise, administrative sanctions related to high levels of risk at work are avoided, as indicated by Apaydin et al. (2018) and Sarkar et al. (2021) in the agriculture sector.

Finally, the relationship in $H_{8}$ between $E S \rightarrow E n S$ is also directly significant with $\beta=0.298$; however, there is also an indirect effect through $S S$ of 0.367 , which gives a total effect of 0.665 , and it is the highest in the model. These findings are significant because the indirect effect is bigger than the direct effect, indicating the high importance of $S S$ for warrantee economic benefits for the maquiladora. The above indicates that by complying with government regulations, reducing the pollutants emission into the environment, and giving good use to energy, reducing costs in developing new products is achieved directly and indirectly through $S S$. Our findings support the reports from Sajeev and Kaur [46] and Sarkar et al. (2021), which mention that environmental aspects make companies grow economically.

\section{From the sensitivity analysis}

Table 6 illustrates the sensitivity analysis, and based on its information, the following can be concluded. Managers should effort to obtain $C I+$ since there is a probability of 0.442 of receiving $E n S+, 0.349$ of $S S+, 0.419$ of $E S+$, 0.465 of $M \& E+$, and 0.488 of $S T+$. In other words, implementing $C I$ tools such as Kaizen and Gemba in production lines is traduced as a cost reduction in new product development, production process, and resource consumption. In addition, companies get better safety and morale in employees, who observe that the company has a social responsibility and cares about their well-being. Also, $C I$ facilitates other LMTs implementation, such as Poca-yoke, Jidoka, and Andon, in the workplace and encourages the development of TPM to improve OEE and automation levels that avoid waste errors.

Another group of LMTs is the STs that integrate Pokayoke, Andon, and visual management. It is observed that $S T+$ can promote $E n S+$ with a probability of 0.514 , $S S+$ with $0.543, E S+$ with 0.400 , and $M \& E+$ with 0.657 , being in the latter where it has a more significant direct effect. That is, facilitating the work of the operators using adequate signals, clear and precise instructions for the activities and operation of machines, and mechanisms that avoid making mistakes, guarantees to obtain a reduction in production costs, low rejects orders shipped, and problems with adverse environmental impact. However, $S T$ also increases the motivation and morale of the workers due to the safety conditions that exist in the workplace; in other words, $S T$ facilitates $S S$.

The efforts that managers make to obtain $S T+$ are not associated with $E n S-, S S-, E S-$, or $M \& E-$, since the conditional probabilities are low or null. In other words, $S T+$ always offers positive results associated with sustainability. That asseveration is verified by observing that when $S T$-occurs, $E n S+, S S+, E S+$, or $M \& E+$ cannot happen either since the probabilities are low or null. However, $S T$ - does represent a probability of obtaining $E n S$ - at $0.452, S S-$ at $0.571, E S-$ at 0.364 , and $M \& E-$ at 0.559 , which is a risk for the company's sustainability.

$M \& E$ tools such as TPM, Jidoka, and OEE are also essential to achieve a sustainable performance for the company if $M \& E+$ occurs. If $M \& E+$, then there is a probability of 0.545 to obtaining $E n S+, 0.545$ of $S S+$, and 0.364 of $E S+$. In other words, TPM programs that can generate high levels of OEE and automation generate a reduction in production costs, material handling, order rejections, and administrative penalties. In addition, $M \& E+$ generates greater employee safety in their workplace, with high morale and motivation and better quality in products.

It is observed that $M \& E+$ is not associated with $E n S-$, $S S-$, and $E S-$, since the probabilities are zero. Also, scenarios where $M \& E$ - occurs are not associated with $E n S+$, $S S+$ y $E S+$, but $M \& E$ - can motivate that $E n S$ - occurs with a probability of $0.500, S S$ - with 0.588 , and $E S$ - with 0.559 , which shows how vital it is to have machines in working conditions that avoid generating waste and reprocessing.

However, obtaining one type of sustainability allows generating another. For example, if $E S+$ occurs, then there is a 0.526 probability that $E n S+$ and $S S+$ occur. In other 
words, if the emission of solid, liquid, or gas pollutants is reduced, then there will be a reduction in costs associated with administrative penalties, an increase in corporative image and financial income. Also, workers will feel safe in their employment and will be motivated to do their job well. Additionally, if $E S+$ occurs, then $E n S$ - and $S S$ - do not happen since the probabilities are minimal.

Also, observe that $E S$ - is not associated with $E n S+$ and $S S+$, but $E S-$ scenario favors adverse situations with a probability of 0.500 for $E n S$ - and 0.611 for $S S$ - . In conclusion, maquiladoras need to invest in $E S+$ because that scenario always guarantees financial and social benefits. Here is important to note that ES + is highly associated with SS +, agreeing with the report of Sarkar et al. (2021).

Finally, observe that $S S+$ favors the occurrence of $E n S+$ with a probability of 0.429 and never is associated with $E n S-$. In the same way, $S S-$ is not associated with $E n S+$ and favors the occurrence of $E n S$ - with a probability of 0.526 . In other words, managers can be sure that the programs for $S S$ they establish will always bring them financial benefits.

Based on the above conclusions, the following is recommended to the maquiladora industry:

1. Managers should follow up on the continuous improvement programs they implement. They should always make comparisons of the metrics and parameters they had before and after each improvement.

2. Improvement programs are enablers for establishing TS, $\mathrm{M} \& \mathrm{E}$, and sustainability, so investments made in this area are fully justified.

3. TS is an enabler of good management programs associated with $M \& E$ conservation and sustainability.

4. $M \& E$ is an enabler for the different types of sustainability, so its investments are justified with higher product quality and less reprocessing.

\section{Limitations and future research}

Many tools integrate LM, and this research reports only eight tools, integrated into three more generic ones (second-order variables). Future research will incorporate LMTs associated with human resources, product quality, and material flow in the production process, hoping to increase the explanatory power in economic, environmental, and social sustainability.

Supplementary Information The online version contains supplementary material available at https://doi.org/10.1007/s11356-022-18978-6.

Author contribution Jorge Luis García-Alcaraz: conceptualization, methodology, validation, investigation, resources, writingoriginal draft, writing - review and editing, supervision, and project administration. Adrián Salvador Morales García: validation, resources, visualization. José Roberto Díaz-Reza: methodology, validation, investigation, resources, data curation, and writing—original draft. Emilio Jiménez Macías: methodology, formal analysis, investigation, data curation, writing - original draft, and writing - review and editing. Carlos Javierre Lardies: conceptualization, formal analysis, and data curation. Julio Blanco Fernández: formal analysis and visualization.

Funding Adrián Salvador Morales García received a scholarship for his Master's degree in Industrial Engineering at the Autonomous University of Ciudad Juarez from the Mexican National Council for Science and Technology (CONACYT) under the grant number 858463 .

Data availability The questionnaire used in this research is available at a repository and can be accessed at: https://doi.org/10.6084/m9.figsh are.14462163, and the data set used in the structural equation model is available at this link: https://doi.org/10.6084/m9.figshare.14462214.

\section{Declarations}

Ethics approval Not applicable.

Consent to participate Not applicable.

Consent for publication Not applicable.

Competing interests The authors declare no competing interests.

\section{References}

Abed, A. M., Elattar, S., Gaafar, T. S., \& Alrowais, F. (2020). Artificial poka-yoke increases process reliability via a hybrid of the neural network with arima results. International Journal of Mechanical and Production Engineering Research and Development, 10(2): 931-954. https://doi.org/10.24247/ijmperdapr202092

Agrawal R, Nath V (2020) Agility and lean practices as antecedents of supply chain social sustainability. Int J Oper Prod Manag 40(10):1589-1611. https://doi.org/10.1108/IJOPM-09-2019-0642

Ajibike WA, Adeleke AQ, Mohamad F, Bamgbade JA, Nawi MNM, Moshood TD (2021) An evaluation of environmental sustainability performance via attitudes, social responsibility, and culture: a mediated analysis. Environ Challenges 4:100161. https://doi.org/ 10.1016/j.envc. 2021.100161

Akbar, S., \& Ahsan, K. (2020). Investigation of the challenges of implementing social sustainability initiatives: a case study of the apparel industry. Social Responsibility Journal 17(3):343-366. https://doi.org/10.1108/SRJ-09-2019-0291

Alsayegh, M. F., Rahman, R. A., \& Homayoun, S. (2020). Corporate economic, environmental, and social sustainability performance transformation through ESG disclosure. Sustainability (Switzerland), 12(9), Article 3910. https://doi.org/10.3390/su12093910

Antony, J., Sunder M, V., Cudney, E., \& Laux, C. (2019). Linking lean six sigma with green and environmental sustainability. in The Ten Commandments of Lean Six Sigma (pp. 101-106). Emerald Publishing Limited. https://doi.org/10.1108/978-1-78973-687820191011

Apaydin M, Bayraktar E, Hossary M (2018) Achieving economic and social sustainability through hyperconnectivity. Benchmark: Int J 25(9):3607-3627. https://doi.org/10.1108/BIJ-07-2017-0205

Arabeyyat OS, Haffar M, Al-Qwasmeh L, Al-Hyari KA, Abu Zaid MK (2019) The applications of Kaizen methods in project settings: 
applied study in Jordan. TQM J 31(5):831-849. https://doi.org/ 10.1108/TQM-03-2019-0078

Arredondo-Soto KC, Sanchez-Leal J, Reyes-Martinez RM, SalazarRuíz E, Maldonado-Macias AA (2018) World class remanufacturing productions systems: an analysis of Mexican maquiladoras. Adv Intell Syst Comput 606:153-161

Arslan M (2020) Corporate social sustainability in supply chain management: a literature review. J Glob Responsib 11(3):233-255. https://doi.org/10.1108/JGR-11-2019-0108

Avelar-Sosa L, Mataveli M, García-Alcaraz JL (2018) Structural model to assess the relationship of manufacturing practices to delivery time in supply chains. S Afr J Ind Eng 29(4):218-229. https://doi. org/10.7166/29-4-1670

Barash MM (1990) Poka-yoke: Improving product quality by preventing defects: N.K. Shimbun, Editor Productivity Press, ( 1988 xiii + 282 pp. \$59.95. J Manuf Syst 9(2):178-179. https://doi.org/10. 1016/0278-6125(90)90033-E

Ben Ruben, R., Nagapandi, P., \& Nachiappan, S. (2021). Modelling and analysis of barriers of lean sustainability in metal manufacturing organizations. Materials Today: Proceedings. 45(7):6807-6812 https://doi.org/10.1016/j.matpr.2020.12.980

Campos-Guzmán V, García-Cáscales MS, Espinosa N, Urbina A (2019) Life Cycle Analysis with Multi-Criteria Decision Making: a review of approaches for the sustainability evaluation of renewable energy technologies. Renew Sustain Energy Rev 104:343-366. https://doi.org/10.1016/j.rser.2019.01.031

Chen Z, Bidanda B (2019) Sustainable manufacturing productioninventory decision of multiple factories with JIT logistics, component recovery and emission control. Transportation Research Part e: Logist Transp Rev 128:356-383. https://doi.org/10.1016/j. tre.2019.06.013

Colazo J (2020) Changes in communication patterns when implementing lean. Int J Qual Reliab Manag 38(1):296-316. https://doi.org/ 10.1108/IJQRM-10-2019-0323

Dalton, J. (2019). Great Big Agile: An OS for Agile Leaders (pp. 175176). Apress. New York, USA. https://doi.org/10.1007/978-14842-4206-3_32

de Oliveira RI, Sousa SO, de Campos FC (2019) Lean manufacturing implementation: bibliometric analysis 2007-2018. Int J Adv Manuf Technol 101(1-4):979-988. https://doi.org/10.1007/ s00170-018-2965-y

Faber M (2020) Robots and reshoring: Evidence from Mexican labor markets. J Int Econ 127:103384. https://doi.org/10.1016/j.jinteco. 2020.103384

Farooq MS, Salam M, Fayolle A, Jaafar N, Ayupp K (2018) Impact of service quality on customer satisfaction in Malaysia airlines: A PLS-SEM approach. J Air Transp Manag 67:169-180. https://doi. org/10.1016/j.jairtraman.2017.12.008

Fortuny-Santos, J., López, P. R. D. A., Luján-Blanco, I., \& Chen, P. K. (2020). Assessing the synergies between lean manufacturing and Industry 4.0. Direccion Y Organizacion 71 (2020): 71-86. https:// doi.org/10.37610/dyo.v0i71.579

Free C, Cuganesan S (2021) Employees' identification and management control systems: a case study of modern policing. Acc Audit Accountability J 34(1):31-53. https://doi.org/10.1108/ AAAJ-04-2020-4490

Fundin A, Eriksson Y (2018) Visual management for a dynamic strategic change. J Organ Chang Manag 31(3):712-727. https://doi. org/10.1108/JOCM-05-2016-0103

Gámez, M. R. V., \& González, J. J. G. (2016). Public social responsability as a key element in employment policy. CIRIEC-Espana Revista de Economia Publica, Social y Cooperativa, 87(1), 11-38. https://www.scopus.com/inward/record.uri?eid=2-s2.0-85000 961954\&partnerID $=40 \& \mathrm{md} 5=26761 \mathrm{e} 3 \mathrm{e} 646 \mathrm{f} 1791 \mathrm{~d} 64189073$ $0 \mathrm{~d} 42 \mathrm{~d} 3 \mathrm{a}$
Garcia-Alcaraz JL, Maldonado-Macias AA, Alor-Hernandez G, Sanchez-Ramirez C (2017) The impact of information and communication technologies (ICT) on agility, operating, and economical performance of supply chain. Adv Prod Eng Manag 12(1):2940. https://doi.org/10.14743/apem2017.1.237

García-Alcaraz JL, Martínez-Loya V, Díaz-Reza JR, Blanco-Fernández J, Jiménez-Macías E, López AJG (2020) Effect of ICT integration on SC flexibility, agility and company' performance: the Mexican maquiladora experience. Wireless Netw 26(7):48054818. https://doi.org/10.1007/s11276-019-02068-6

Gillam SL, Holbrook S, Mecham J, Weller D (2018) Pull the andon rope on working memory capacity interventions until we know more. Lang Speech Hear Serv Sch 49(3):434-448. https://doi. org/10.1044/2018_LSHSS-17-0121

Girón, A., Kazemikhasragh, A., Cicchiello, A. F., \& Panetti, E. (2021). Sustainability reporting and firms' economic performance: evidence from Asia and Africa. Journal of the Knowledge Economy 12(4):1741-1759. https://doi.org/10.1007/ s13132-020-00693-7

Henao R, Sarache W, Gómez I (2019) Lean manufacturing and sustainable performance: trends and future challenges. J Clean Prod 208:99-116. https://doi.org/10.1016/j.jclepro.2018.10.116

Hoffman, J. I. E. (2019). Chapter 9 - Outliers and Extreme Values. In J. I. E. Hoffman (Ed.), Basic Biostatistics for Medical and Biomedical Practitioners (2 edition ed., pp. 149-155). Academic Press. https://doi.org/10.1016/B978-0-12-817084-7.00009-7

Iacobucci D, Posavac SS, Kardes FR, Schneider MJ, Popovich DL (2015) Toward a more nuanced understanding of the statistical properties of a median split. J Consum Psychol 25(4):652-665. https://doi.org/10.1016/j.jcps.2014.12.002

IMMEX. (2021). INDEX Juárez - Monthly statistic information (January 22, 2021) IMMEX. Ciudad Juárez, Chihuahua, Mexico.

Irfan M, Hassan M, Hassan N (2018) Unravelling the fuzzy effect of economic, social and environmental sustainability on the corporate reputation of public-sector organizations: a case study of Pakistan. Sustainability (Switzerland) 10(3):769. https://doi.org/ $10.3390 /$ su 10030769

Kiran, D. R. (2020). Chapter 11 - Kaizen and continuous improvement. In D. R. Kiran (Ed.), Work Organization and Methods Engineering for Productivity (pp. 155-161). Butterworth-Heinemann. Oxford, United Kingdom. https://doi.org/10.1016/B978-0-12819956-5.00011-X

Kock N (2019b) From composites to factors: Bridging the gap between PLS and covariance-based structural equation modelling. Inf Syst J 29(3):674-706. https://doi.org/10.1111/isj.12228

Kock, N. (2018). WarpPLS 6.0 User Manual. ScriptWarp Systems. Laredo, TX, USA.

Kock, N. (2019a). Factor-based structural equation modeling with WarpPLS. Australasian Marketing Journal (AMJ) 27(1):57-63. https://doi.org/10.1016/j.ausmj.2018.12.002

Kurdve M, Harlin U, Hallin M, Söderlund C, Berglund M, Florin U, Landström A (2019) Designing visual management in manufacturing from a user perspective. Procedia CIRP 84:886-891. https://doi.org/10.1016/j.procir.2019.04.310

Leffakis ZM, El-Khalil R, Hong PC (2020) Impact of improvement tools on standardization and stability goal practices. $\mathrm{J}$ Manuf Technol Manag 31(4):705-723. https://doi.org/10.1108/ JMTM-08-2019-0289

Leksic I, Stefanic N, Veza I (2020) The impact of using different lean manufacturing tools on waste reduction. Adv Prod Eng Manag 15(1):81-92. https://doi.org/10.14743/APEM2020.1.351

Liu, Q., \& Mouri, M. (2015). Power of GEMBA. In Q. Liu \& M. Goh (Eds.), TA-Q-BIN: Service Excellence and Innovation in Urban Logistics (pp. 59-83). Springer Singapore, Singapure. https://doi. org/10.1007/978-981-287-673-7_5 
Maama H, Doorasamy M, Rajaram R (2021) Cleaner production, environmental and economic sustainability of production firms in South Africa. J Clean Prod 298:126707. https://doi.org/10.1016/j. jclepro.2021.126707

Makhija, A., Wickramasinghe, C., \& Tiwari, M. (2021). 5 - Visual management. In P. Jana \& M. Tiwari (Eds.), Lean Tools in Apparel Manufacturing (pp. 131-208). Woodhead Publishing, Sawston, United Kingdom. https://doi.org/10.1016/B978-0-12-819426-3. 00009-6

Mallampati M, Srivinivas K, Tirumala Krishna M (2018) Design process to reduce production cycle time in product development. IAES Int J Artif Intell 7(3):125-129. https://doi.org/10.11591/ ijai.v7.i3.pp125-129

Martínez-Loya, V., Díaz-Reza, J. R., García-Alcaraz, J. L., \& TapiaCoronado, J. Y. (2018). SEM: a global technique - case applied to TPM. In J. L. García-Alcaraz, G. Alor-Hernández, A. A. Maldonado-Macías, \& C. Sánchez-Ramírez (Eds.), New Perspectives on Applied Industrial Tools and Techniques (pp. 3-22). Springer International Publishing, New York City, NY, USA. https://doi. org/10.1007/978-3-319-56871-3_1

Moore LE, Walsh L, Corbin TP, Kattman B (2012) Visual workplace practices positively impact business processes. Benchmarking: An Int J 19(3):412-430. https://doi.org/10.1108/14635771211243021

Morales-García AS, Díaz-Reza JR, García-Alcaraz JL (2021) Effect of TPM and OEE on the social performance of companies. Stud Comput Intell 966:119-141 https://doi.org/10.1007/ 978-3-030-71115-3_6

Morales García, A., Garcia Alcaraz, J., \& Díaz Reza, J. (2021). Dataset: Effect of Lean Manufacturing Tools on the Company's Environmental Performance. Dataset. Version 1. https://doi.org/10. 6084/m9.figshare. 14462214

Morales García, A., García Alcaraz, J., \& Díaz Reza, J. (2021). Survey: Effect of Lean Manufacturing Tools on the Company's Environmental Performance. Survey Version 1 on repository. https://doi. org/10.6084/m9.figshare.14462163

Morell-Santandreu, O., Santandreu-Mascarell, C., \& García-Sabater, J. (2020). Sustainability and kaizen: business model trends in healthcare. Sustainability (Switzerland), 12(24), 1-28, Article 10622. https://doi.org/10.3390/su122410622

Morselli, A., \& Ventura, M. (2017). Measuring Corporate Social Responsability disclosure and the financial crisis in Italy. Comparison of the two years prior to the crisis (2006) and the two years since the onset of the crisis (2010). Journal of Applied Economic Sciences, 12(4), 1025-1037. https://www.scopus.com/inward/ record. uri?eid=2-s2.0-85031497109\& partnerID=40\&md5= f0b1571de1863104c290696613ea9064

Munguía Vega NE, Flores Borboa VS, Zepeda Quintana DS, Velazquez Contreras LE (2019) Assessing the effectiveness of integrating ergonomics and sustainability: a case study of a Mexican maquiladora. Int J Occup Saf Ergon 25(4):587-596. https://doi.org/10. 1080/10803548.2017.1419589

Negulescu O, Doval E (2016) A matrix of investments in social responsibility and sustainability: an empirical case study in Romania. J Global Bus Adv 9(2):131-145. https://doi.org/10.1504/JGBA. 2016.075709

Paroutis, S., \& Knight, E. (2019). How visual methods can enhance our understanding of strategy and management. In Standing on the Shoulders of Giants (Vol. 11, pp. 77-90). Emerald Publishing Limited. https://doi.org/10.1108/S1479-838720190000011007

Pötters P, Schmitt R, Leyendecker B (2018) Effectivity of quality methods used on the shop floor of a serial production-how important is Poka Yoke?. Total Qual Manag Bus Excell 29(9-10):1200-1212. https://doi.org/10.1080/14783363.2018.1488559

Romero D, Gaiardelli P, Powell D, Wuest T, Thürer M (2019) Rethinking jidoka systems under automation \& learning perspectives in the digital lean manufacturing world. IFAC-PapersOnLine 52(13):899-903. https://doi.org/10.1016/j.ifacol.2019.11.309

Romero, D., Gaiardelli, P., Wuest, T., Powell, D., \& Thürer, M. (2020, 2020//). New Forms of Gemba Walks and Their Digital Tools in the Digital Lean Manufacturing World. Advances in Production Management Systems. Towards Smart and Digital Manufacturing. Springer International Publishing, New York City, NY, USA.

Rossini M, Audino F, Costa F, Cifone FD, Kundu K, Portioli-Staudacher A (2019) Extending lean frontiers: a kaizen case study in an Italian MTO manufacturing company. Int J Adv Manuf Technol 104(5):1869-1888. https://doi.org/10.1007/s00170-019-03990-x

Sahoo S (2019) Assessment of TPM and TQM practices on business performance: a multi-sector analysis. J Qual Maint Eng 25(3):412-434. https://doi.org/10.1108/JQME-06-2018-0048

Sarkar A, Azim JA, Asif AA, Qian L, Peau AK (2021) Structural equation modeling for indicators of sustainable agriculture: Prospective of a developing country's agriculture. Land Use Policy 109:105638. https://doi.org/10.1016/j.landusepol.2021.105638

Saurin TA, Marodin GA, Ribeiro JLD (2011) A framework for assessing the use of lean production practices in manufacturing cells. Int J Prod Res 49(11):3211-3230. https://doi.org/10.1080/00207 543.2010.482567

Saurin TA, Ribeiro JLD, Vidor G (2012) A framework for assessing poka-yoke devices. J Manuf Syst 31(3):358-366. https://doi.org/ 10.1016/j.jmsy.2012.04.001

Schönborn G, Berlin C, Pinzone M, Hanisch C, Georgoulias K, Lanz M (2019) Why social sustainability counts: the impact of corporate social sustainability culture on financial success. Sustain Prod Consum 17:1-10. https://doi.org/10.1016/j.spc.2018.08.008

Sethi P, Chakrabarti D, Bhattacharjee S (2020) Globalization, financial development and economic growth: perils on the environmental sustainability of an emerging economy. J Policy Model 42(3):520 535. https://doi.org/10.1016/j.jpolmod.2020.01.007

Shan, W., \& Wang, J. (2019). The effect of environmental performance on employment: evidence from China's manufacturing industries. International Journal of Environmental Research and Public Health, 16(12), Article 2232. https://doi.org/10.3390/ijerph1612 2232

Singh, S., Khamba, J. S., \& Singh, D. (2020). Analysis and directions of OEE and its integration with different strategic tools. Proceedings of the Institution of Mechanical Engineers, Part E: Journal of Process Mechanical Engineering https://doi.org/10.1177/09544 08920952624

Suárez-Barraza MF, Ramis-Pujol J, Estrada-Robles M (2012) Applying Gemba-Kaizen in a multinational food company: a process innovation framework. Int J Qual Serv Sci 4(1):27-50. https:// doi.org/10.1108/17566691211219715

Suh, C. J., \& Lee, I. T. (2018). An empirical study on the manufacturing firm's strategic choice for sustainability in SMEs. Sustainability, 10(2), 572. https://www.mdpi.com/2071-1050/10/2/572

Taucean, I. M., Miclea, S., Ivascu, L., \& Negrut, M. L. (2021). Analysis of interrelationship for lean and sustainability principles and implications. In Advances in Intelligent Systems and Computing (Vol. 1221 AISC, pp. 217-227).

Tekin, M., Arslandere, M., Etlioğlu, M., Koyuncuoğlu, Ö., \& Tekin, E. (2019, 2019//). An application of SMED and jidoka in lean production. Proceedings of the International Symposium for Production Research 2018, Springer Cham. New York City, NY, USA.

Tezel A, Aziz Z (2017) Visual management in highways construction and maintenance in England. Eng Constr Archit Manag 24(3):486-513. https://doi.org/10.1108/ECAM-02-2016-0052

Tezel A, Koskela L, Tzortzopoulos P (2016) Visual management in production management: a literature synthesis. J Manuf Technol Manag 27(6):766-799. https://doi.org/10.1108/ JMTM-08-2015-0071 
Trujillo-Gallego M, Sarache W (2019) An integral GSCM index for assessment of environmental performance in manufacturing companies. Benchmark-an Int J 26(6):1948-1971. https://doi.org/10. 1108/bij-11-2018-0352

Uddameri V, Honnungar V (2010) An optimisation model for transportation of hazardous wastes. Int J Environ Technol Manage 13(1):4-20. https://doi.org/10.1504/IJETM.2010.032532

Vaithyasubramanian S, Paul MJ, Babu RD, Kirubhashankar CK (2020) Job Morale - Employees Energy Driven Tool for Better Productivity in Automotive Industry. Webology 17(2):621-630. https://doi. org/10.14704/WEB/V17I2/WEB17056

Velázquez L, Munguía N, Navarrete DLÁ, M., \& Zavala, A. (2006) An overview of sustainability practices at the maquiladora industry in Mexico. Manag Environ Qual: Int J 17(4):478-489. https://doi. org/10.1108/14777830610670535

Velazquez L, Munguia N, Zavala A, Esquer J, Will M, Delakowitz B (2014) Cleaner production and pollution prevention at the electronic and electric Mexican maquiladora. Manag Environ Qual: Int J 25(5):600-614. https://doi.org/10.1108/MEQ-02-2013-0011
Yadav G, Kumar A, Luthra S, Garza-Reyes JA, Kumar V, Batista L (2020) A framework to achieve sustainability in manufacturing organisations of developing economies using industry 4.0 technologies' enablers. Comput Ind 122:103280. https://doi.org/10. 1016/j.compind.2020.103280

Younus, A., Pervez, H., Ali, Y., \& Khan, A. U. (2020). Impact of Lean, Six Sigma and environmental sustainability on the performance of SMEs. International Journal of Productivity and Performance Management 70(8): 2294-2319.https://doi.org/10.1108/ IJPPM-11-2019-0528

Publisher's note Springer Nature remains neutral with regard to jurisdictional claims in published maps and institutional affiliations. 